\title{
INFLUENCE OF ORGANIC ADDITIVES ON THE EFFICIENCY OF PROCESS OF PREPARATION OF MOLDING COMPOUNDS FOR MAGNESIUM SILICATE CERAMIC
}

\author{
K. G. Zemlyanoi ${ }^{1}$ and N. A. Moskovskikh ${ }^{1}$
}

Translated from Novye Ogneupory, No. 12, pp. 7 - 11, December, 2012.

Original article submitted February 17, 2012.

The influence of Litoplast series additives on the rheological properties of clay-free magnesium silicate slip is investigated. The use of Litpolast grinding intensifiers makes it possible to decrease the duration of grinding of commercial slip by $3-7 \%$. The use of Litoplast $\mathrm{M}$ dispersing agents separately and in combination with inorganic surface-active substances substantially reduces the moisture content of commercial slip without the slip losing its rheological properties. This substantially reduces the energy costs in subsequent production of molding compounds.

Keywords: slip, plasticity, flow, density, drying, grinding intensifiers, diluents

One of the most energy-intensive processes in production in the mining and ceramic branches and in the construction materials industry is the process of comminution. The quality of future articles and the energy costs of conversion steps depend on the indicators of this process, such as efficiency and rate. Traditionally, the productivity of comminution is improved by modernization and optimization of the operation of grinding equipment, but even in the studies carried out by P. A. Rebinder and his school, the founder of the international school of adsorption reduction of hardness under the influence of surface-active substances, it has been noted that the introduction of organic substances in the course of grinding tends to increase the intensity of the process.

In order to establish the efficiency of organic intensifiers in grinding and separation of particles it is important to understand the process of comminution and the mechanism by which intensifiers function. By strength is understood the capacity of a material to resist failure under the effect of an applied load. Failure of a material in the course of a strength test is considered a process involving the growth of cracks and the concentration of stresses near the cracks, under the influence of which the surface of the material comes to be covered by a network of micro-cracks. If the width of the micro-cracks exceeds some magnitude (Griffith's cracks), the micro-cracks will subsequently grow upon the application of

\footnotetext{
1 FGAOU VPO Ural Federal University, Yekaterinberg, Russia.
}

mechanical actions, inducing failure of the material. The critical magnitude of micro-cracks differs for different materials and depends on the structure and state of the solid phase, the dimensions of the crystals, whether there is a glass phase present, and other factors.

The molecules of an intensifier which have entered a micro-crack of a substance that has been subjected to grinding exerts a wedging effect and therefore tends to increase the efficiency of the grinding process. Adsorbed molecules or ions penetrate from the environment to a significant depth into the deformed zone of a solid through the numerous micro-cracks that appear in the course of deformation. The greater the stresses that have arisen in a solid in the course of its deformation, the stronger will be the effect of adsorptive reduction of hardness.

Organic substances with low surface energy, such as surface-active substances that effectively wet the surface of a comminuted material and create adsorbed interlayers on its surface, exert an active wedging effect in the narrowest sections of the slits if they are accessible to surfactants of monomolecular dimensions. Once the external forces are removed, there occur difficulties, and in very case, a slow-down in washing away of nucleated sections of the micro-slits under the influence of the adsorbed layers. The greatest difference in the polarities at the material surfactant interface caused by the negative charge on the surface of oxide materials and the polar structure of the surfactant molecules as well as by the form of the terminal 
radical in the surfactant molecules tends to amplify the effect of reduced hardness of solids.

OOO Poliplast Novomoskovsk, one of the manufacturers of special surfactants for grinding mineral materials, has developed the Litoplast series of grinding intensifiers, which is the latest series of synthetic additives based on sodium and polyalkalene oxide derivatives of polymethylene naphthalene sulfonic acids and polyethylene glycol, which are substances that are synthesized from compounds of differing degrees of polymerization and with different terminal radicals. The surface activity of an additive varies as a function of the degree of polymerization with respect to the interfaces between particular materials. Additives are used in dry or liquid form (aqueous or nonaqueous solution) at a rate of $0.01-0.05$ wt. $\%$ of the comminuted material, scaled on the basis of dry matter.

The objective of the present study is the investigate the action of grinding and dispersing intensifiers produced by OOO Poliplast Novomoskovsk on the rate of grinding of materials and the flow of slip used for the fabrication of technical-grade ceramics. The initial material consists of wastes from the beneficiation of asbestos ore from the Bazhenov deposit (Asbest, Sverdlovsk District), such as natural serpentinite, and forsterite, a product of heat treatment of the latter.

Serpentinite is an aqueous magnesium silicate containing impurities of oxides of iron, aluminum, manganese, nickel, cobalt, copper, chromium, and other minerals, in fact, it is one of the most widespread of all rocks. It is associated with the deposits of many minerals, may be interstitial rock, and, correspondingly, waste generated by the mining industry, in particular, waste from the production of asbestos. Serpentinites may be used in the production of different types of technical-grade ceramic, magnesium metal, magnesium refractories, chemically pure magnesium, active silica, cobalt-nickel concentrate, iron oxide pigments, etc. The chemical and granulometric composition of typical types of serpentinite wastes generated by the asbestos industry are presented in Table 1.

In the raw serpentinite that was studied the differences with differing degree of metamorphism with impurities of diorite, peridotite, carbonates, and talc vein minerals amount to $70.2-95.6 \%$, fibers (asbestos in veinlets and free state) $0-27 \%$, and magnetite (natural iron oxides), $2.2-5.8 \%$; ovurite, chromite, and spinel are also encountered. A total of 12 types of Litoplast series additives were tested as grinding intensifiers, including additives on a water base (I1, I2, I3, $\mathrm{I} 4, \mathrm{I} 5)$ and nonwater-base additives $(\mathrm{O} 1, \mathrm{O} 2, \mathrm{O} 3, \mathrm{O} 4, \mathrm{O}$, O6, O18).

The addition of surfactants in the course of comminution increases the rate of increase of the specific surface of the material $S_{\mathrm{sp}}$. This process may be controlled relative to the specific surface proper and from the granular composition of the material following comminution. Preliminary experimental grinding in a 5-1 metallic ball mill with metallic tumbling balls 16 to $32 \mathrm{~mm}$ in dimension with ratio of ball : material $=7: 1$ was conducted in order to determine the most ef- fective additive that would increase the rate of increase in $S_{\mathrm{sp}}$ in the course of grinding of the test serpentinite materials and the optimal concentration of the additive.

Equal samples of the raw material (each weighing $2 \mathrm{~kg}$ ) with computed quantity of intensifier additive were subjected to grinding over equal lengths of time $(6 \mathrm{hr})$. The quantity of intensifier-additive was determined from the formula

$$
\text { Quantity of Additive }=\frac{\text { weight of material } \times 0.03 \%}{\text { concentration of additive } \times}
$$

Control over the intensity of grinding was achieved by sieve (All-Russia State Standard 6613) and sedimentation (All-Russia State Standard 21216.2) analyses. The results of the sieve analysis are presented in Table 2 and in Fig. 1.

From the data presented here it is evident that the addition of the test additives in the course of grinding affects the intensity of grinding of roasted forsterite in different ways. Of the water-soluble additives, only additive $\mathrm{I} 3$ promoted a decrease in the quantity of the coarse fraction (from 9.8 to 8.7 wt.\%) and an increase in the quantity of the fine fraction (from 72.4 to 74 wt.\%). The nonaqueous additives promoted an acceleration in the grinding of forsterite to a considerable degree, reducing the quantity of the coarse fraction down to $8.0-8.3 \%$ and increasing the quantity of the fine fraction to

\begin{tabular}{|c|c|c|}
\hline \multirow{2}{*}{ Indicator } & \multicolumn{2}{|c|}{ Raw Material } \\
\hline & Serpentinite & Forsterite \\
\hline Moisture content, $\%$ & 0.60 & 0.30 \\
\hline \multicolumn{3}{|c|}{$\begin{array}{l}\text { Granulometric composition, } \\
\text { wt. } \% \text {, fraction, mm: }\end{array}$} \\
\hline$>10$ & 60 & 91.3 \\
\hline$>7$ & 26.7 & 7.06 \\
\hline$>5$ & 11.7 & 1.26 \\
\hline$<5$ & 1.25 & 0.3 \\
\hline \multicolumn{3}{|l|}{ Content, wt.\%: } \\
\hline $\mathrm{MgO}$ & $35.0-37.8$ & $39.1-42.3$ \\
\hline $\mathrm{SiO}_{2}$ & $40.1-45.6$ & $46.0-48.7$ \\
\hline $\mathrm{Fe}_{3} \mathrm{O}_{4}$ & $6.4-8.1$ & $7.8-9.1$ \\
\hline $\mathrm{CaO}$ & $1.1-1.6$ & $1.4-1.8$ \\
\hline $\mathrm{Al}_{2} \mathrm{O}_{3}$ & $1.1-1.4$ & $1.4-1.6$ \\
\hline $\mathrm{R}_{2} \mathrm{O}$ & $1.3-1.8$ & $1.5-1.9$ \\
\hline Lost after calcination & $9.8-11.2$ & - \\
\hline Packed density, $\mathrm{g} / \mathrm{cm}^{3}$ & 1.435 & 1.305 \\
\hline Water absorption, $\%$ & 0.40 & 9.10 \\
\hline Open porosity, $\%$ & 0.6 & 12.6 \\
\hline Apparent density, $\mathrm{g} / \mathrm{cm}^{3}$ & 1.38 & 1.22 \\
\hline
\end{tabular}

TABLE 1. Characteristics of Raw Ore 


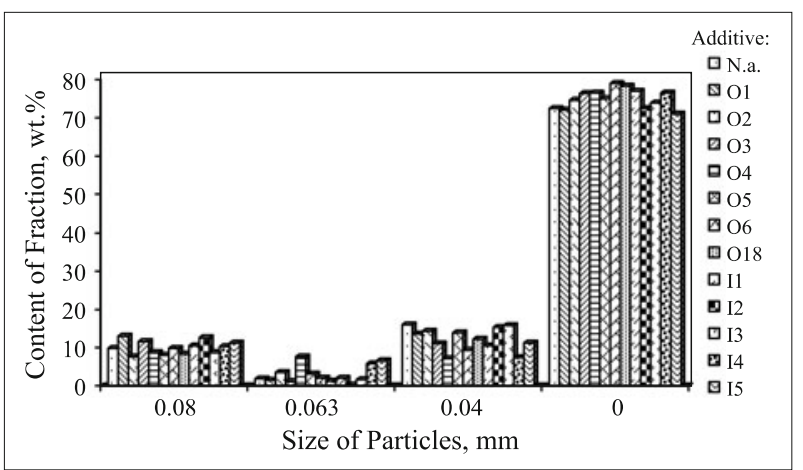

Fig. 1. Distribution of forsterite particles by fraction following grinding, according to data of sieve analysis (N.a. — no additive).

$78-79 \%$. From the results of the studies additive O6 turned out to be most optimal.

The data of the sedimentation analysis (Table 3, Fig. 2) confirm the data of the sieve analysis both as regards an increase in the yield of fine fractions in trials using additives and as regards the high efficiency of the nonaqueous additives.

The following conclusions may be drawn on the basis of the studies:

- introduction of surfactants that are grinding intensifiers produces a $3-7 \%$ increase in the yield of fine fractions under comparable grinding conditions or a decrease in the duration of comminution of the material needed to achieve the same indicators of the granular composition

TABLE 2. Sieve analysis of Fractional Composition of Products of Grinding of Forsterite.

\begin{tabular}{lcccc}
\hline \multirow{2}{*}{ Additive } & \multicolumn{4}{c}{ Content, wt.\%, fractions, mm } \\
\cline { 2 - 5 } & $>0.08$ & $0.08-0.063$ & $0.063-0.04$ & $<0.04$ \\
\hline N.a.* & 9.8 & 1.8 & 16.0 & 72.4 \\
I1 & 10.5 & 2.0 & 10.5 & 77.0 \\
I2 & 12.6 & 0.2 & 15.3 & 72.4 \\
I3 & 8.7 & 1.6 & 15.8 & 74.0 \\
I4 & 10.3 & 5.8 & 7.4 & 76.5 \\
I5 & 11.2 & 6.6 & 11.2 & 71.0 \\
O1 & 13.0 & 1.4 & 13.6 & 72.0 \\
O2 & 7.58 & 3.5 & 14.3 & 74.6 \\
O3 & 11.6 & 1.1 & 10.8 & 76.4 \\
O4 & 8.7 & 7.6 & 7.1 & 76.5 \\
O5 & 8.0 & 3.1 & 14.0 & 75.0 \\
O6 & 9.8 & 2.0 & 9.3 & 79.0 \\
O18 & 8.3 & 1.2 & 12.2 & 78.3 \\
\hline
\end{tabular}

* No additive.

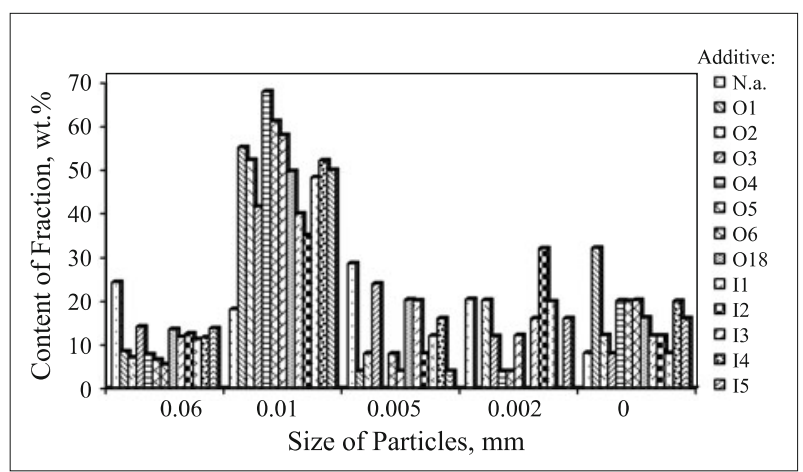

Fig. 2. Distribution of forsterite particles by fraction following grinding, according to data of sedimentation analysis (N.a. - no additive).

- additives on a nonaqueous base are more effective in the case of comminution of roasted serpentinite (forsterite)

The next stage of the technological process in the production of technical-grade ceramic after grinding is that of fabrication of precursor slip for the production of molding compound from which ceramic articles are then fabricated. Requirements as regards moisture content, flow, density, and sedimentation stability are imposed on the slip. Complex additives that will support the set of functional properties must be used in order to ensure the rheological properties of clay-free slip.

There are five types of diluents of different organic natures and physicochemical properties in the Litoplast $\mathrm{M}$ series. The degree of efficiency of their action depends on the mineral composition of the ore. The diluents constitute com-

TABLE 3. Sedimentation analysis of Fractional Composition of Products of Grinding of Forsterite.

\begin{tabular}{lccccc}
\hline \multirow{2}{*}{ Additive } & \multicolumn{5}{c}{ Content, wt.\%, fractions, mm } \\
\cline { 2 - 6 } & $>0,06$ & $0,06-0,01$ & $0,01-0,005$ & $0,005-0,002$ & $<0,002$ \\
\hline N.a. & 24,4 & 18,2 & 28,7 & 20,5 & 8,2 \\
I1 & 11,8 & 40,0 & 20,2 & 16,1 & 12,1 \\
I2 & 12,6 & 35,2 & 8,0 & 32,2 & 12,1 \\
I3 & 11,3 & 48,3 & 12,1 & 20,0 & 8,1 \\
I4 & 11,7 & 52,2 & 16,1 & 0,0 & 20,1 \\
I5 & 13,8 & 50,0 & 4,0 & 16,1 & 16,1 \\
O1 & 8,5 & 55,2 & 4,0 & 0,0 & 32,3 \\
O2 & 7,1 & 52,3 & 8,1 & 20,3 & 12,2 \\
O3 & 14,2 & 41,6 & 24,1 & 12,0 & 8,0 \\
O4 & 7,8 & 68,0 & 0,0 & 4,0 & 20,2 \\
O5 & 6,6 & 61,2 & 8,0 & 4,0 & 20,1 \\
O6 & 5,5 & 58,0 & 4,0 & 12,2 & 20,3 \\
O18 & 13,6 & 49,7 & 20,4 & 0,0 & 16,3 \\
\hline
\end{tabular}

* No additive. 
plexes of surfactants based on polymethylene naphthalene sulfonates, such as hybrid polymers that formally possess the basic features of polyester carboxylates with lengthy main chain consisting of several types of elementary bonds, such as sulfo groups, to assure high adsorptive activity and reduce the dependence on free alkalis and polyalkylene oxide, or some other type of side chain to assure a steric effect and (or) impart additional properties.

The possibility of varying the thickness of the solvate shells around the hydrated particles is the basis for control of the structuro-mechanical, rheological, and technological properties of the raw materials. The processes that affect the

TABLE 4. Composition and Properties of Initial Slip

\begin{tabular}{|c|c|c|}
\hline \multirow{2}{*}{ Indicator } & \multicolumn{2}{|r|}{ Slip } \\
\hline & serpentinite & forsterite \\
\hline Moisture content, $\%$ & 60,88 & 44,65 \\
\hline Density, $\mathrm{g} / \mathrm{cm}^{3}$ & 1,6 & 1,6 \\
\hline Flowability, mm & 195 & p200 \\
\hline Viscosity, sec & No flow & 59,5 \\
\hline Stability of water separation, $\mathrm{ml} /$ day & $<10$ & 112 \\
\hline \multicolumn{3}{|l|}{ Fractional composition, $\%$} \\
\hline \multicolumn{3}{|l|}{ sieve, fraction, mm: } \\
\hline 0,08 & 0,08 & $\begin{array}{l}100 \% \text { transit } \\
\text { through screen }\end{array}$ \\
\hline 0,063 & 0,06 & \\
\hline 0,04 & 0,06 & \\
\hline$<0,04$ & 99,8 & \\
\hline \multicolumn{3}{|l|}{ sedimentation, fraction, $\mathrm{mm}$} \\
\hline $0,25-0,06$ & 17,26 & 3,92 \\
\hline $0,06-0,01$ & 70,56 & 3,62 \\
\hline $0,01-0,005$ & 0 & 44,22 \\
\hline $0,005-0,002$ & 4,06 & 15,92 \\
\hline$<0,002$ & 8,12 & 32,32 \\
\hline
\end{tabular}

TABLE 5. Dilution of Serpentinite Slip of Litoplast M Series Surfactant*

\begin{tabular}{cccc}
\hline Sample & Quantity of Additive, wt. $\%$ & Density, $\mathrm{g} / \mathrm{cm}^{3}$ & Viscosity, sec \\
\hline Initial slip & 0.0 & 1.40 & No flow \\
1 & 1.0 & 1.40 & 32 \\
2 & 1.0 & 1.35 & 32 \\
3 & 1.0 & 1.40 & 30 \\
4 & 0.5 & 1.40 & 30 \\
5 & 0.5 & 1.35 & 28 \\
\hline
\end{tabular}

* The flowability of all the samples was significantly greater than $200 \mathrm{~mm}$, while the flowability of the initial slip was $195 \mathrm{~mm}$. structuro-mechanical properties of the raw material components are based on ion exchange phenomena. Slip suspensions constitute colloidal systems, are capable of engaging in exchange reactions and sorption of water, and exhibit electrokinetic phenomena. In a colloidal system consisting of a solid phase suspended in a liquid, surfactant diluents are adsorbed preferably on the surface of the individual particles.

The objective of the present study was to obtain superfluid slip with moisture content less than $35 \%$. Two samples of slip were provided, forsterite and serpentinite (Table 4). The selection of diluents involved adding to the initial slip a specified quantity of diluent additive and then determining its properties (Table 5 and Table 6 ).

From the data presented in Tables 5 and 6 it is evident that the use of Litoplast M series surfactant diluents makes it possible to reduce the viscosity of serpentinite slip by $7-13 \%$ and of forsterite slip by $10-30 \%$ while preserving all the technological parameters. It should be noted that as the concentration of additive increases, the viscosity of the slip decreases uniformly (samples $1,3,4,5$ ) or grows uniformly (sample 2).

Samples of diluents 4 and 5 were selected for the next studies; these diluents exhibited he greatest decrease in the

TABLE 6. Dilution of Forsterite Slip of Litoplast M Series Surfactant*

\begin{tabular}{|c|c|c|c|}
\hline Additive (sample) & Quantity of Additive, wt.\% & Density, $\mathrm{g} / \mathrm{cm}^{3}$ & Viscosity, sec \\
\hline Initial slip & 0.0 & 1.75 & 51 \\
\hline \multirow[t]{4}{*}{1} & 0.1 & 1.75 & 50 \\
\hline & 0.2 & 1.70 & 48 \\
\hline & 0.3 & 1.70 & 49 \\
\hline & 0.5 & 1.70 & 45 \\
\hline \multirow[t]{4}{*}{2} & 0.1 & 1.72 & 48 \\
\hline & 0.2 & 1.70 & 48.5 \\
\hline & 0.3 & 1.70 & 49 \\
\hline & 0.5 & 1.70 & 56 \\
\hline \multirow[t]{4}{*}{3} & 0.1 & 1.70 & 49 \\
\hline & 0.2 & 1.70 & 45 \\
\hline & 0.3 & 1.70 & 38 \\
\hline & 0.5 & 1.70 & 39 \\
\hline \multirow[t]{4}{*}{4} & 0.1 & 1.75 & 45 \\
\hline & 0.2 & 1.75 & 38 \\
\hline & 0.3 & 1.75 & 35 \\
\hline & 0.5 & 1.75 & 36 \\
\hline \multirow[t]{4}{*}{5} & 0.1 & 1.75 & 45 \\
\hline & 0.2 & 1.75 & 42 \\
\hline & 0.3 & 1.75 & 40 \\
\hline & 0.5 & 1.75 & 38 \\
\hline
\end{tabular}

* The flowability of all the samples was significantly greater than $200 \mathrm{~mm}$ 
TABLE 7. Selection of Complex Diluents for Forsterite Slip*

\begin{tabular}{cccc} 
Sample & $\begin{array}{c}\text { Quantity of Litoplast M Series } \\
\text { Additive,** wt.\%/g }\end{array}$ & $\begin{array}{c}\text { Density, } \\
\mathrm{g} / \mathrm{cm}^{3}\end{array}$ & $\begin{array}{c}\text { Viscosity, } \\
\mathrm{sec}\end{array}$ \\
\hline 4 & $0.05 / 0.85$ & 1.75 & 39 \\
4 & $0.1 / 1.7$ & 1.70 & 37 \\
4 & $0.3 / 5.1$ & 1.70 & 33 \\
4 & $0.5 / 8.5$ & 1.70 & 31 \\
5 & $0.05 / 0.79$ & 1.70 & 39 \\
5 & $0.1 / 1.58$ & 1.70 & 37 \\
5 & $0.3 / 4.74$ & 1.70 & 35 \\
\hline
\end{tabular}

* In all the cases the flowability of samples 4 and 5 was significantly greater than $200 \mathrm{~mm}$.

** The quantity of phosphonic surfactant additive in samples 4 and 5 amounts to $0.03 / 0.18 \mathrm{wt} . \% / \mathrm{g}$.

TABLE 8. Reduction in Quantity of Phosphonate in Complex Additive due to Use of Litoplast M Series Surfactant in Sample 4*

\begin{tabular}{lccc}
\hline \multicolumn{2}{c}{ Quantity of Additive, wt.\%/g } & $\begin{array}{c}\text { Density, } \\
\mathrm{g} / \mathrm{cm}^{3}\end{array}$ & $\begin{array}{c}\text { Viscosity, } \\
\mathrm{sec}\end{array}$ \\
\cline { 1 - 2 } Litoplast M Series & phosphonic surfactant & 1.75 & 40.5 \\
$0.05 / 0.85$ & $0.01 / 0.06$ & 1.68 & 36 \\
$0.05 / 0.85$ & $0.02 / 0.12$ & 1.75 & 39 \\
$0.05 / 0.85$ & $0.03 / 0.18$ & 1.72 & 41 \\
$0.1 / 1.7$ & $0.01 / 0.06$ & 1.7 & 39 \\
$0.1 / 1.7$ & $0.02 / 0.12$ & 1.7 & 37 \\
$0.1 / 1.7$ & $0.03 / 0.18$ & 1.68 & 38 \\
$0.2 / 3.4$ & $0.01 / 0.06$ & 1.68 & 37 \\
$0.2 / 3.4$ & $0.02 / 0.12$ & 1.75 & 34 \\
$0.03 / 0.51$ & $0.01 / 0.06$ & 1.7 & 32 \\
$0.03 / 0.51$ & $0.02 / 0.12$ & & \\
\hline
\end{tabular}

* In all the cases the flowability was significantly greater than $200 \mathrm{~mm}$.

viscosity of the slips while their density was preserved. Phosphate additives are now used in the fabrication process for dilution of slip, hence the next stage of the investigations was to create a complex additive based on phosphonic surfactant and additives from the Litoplast $\mathrm{M}$ series (Tables 7 and 8). Phosphate additives at a rate of $0.01-0.03 \mathrm{wt} . \%$ were added in the investigation, since a greater amount would have led to a contraction in the sintering time needed for the ceramic. From the data presented in Tables 7 and 8 it is evident that:

- at low concentrations of the organic component (0.05 wt.\%), a complex additive dilutes the slip as a classical electrolyte, i.e., it possesses an optimal quantity of the phosphate component which, if exceeded, leads to an increase in the viscosity

- an increase in the concentration of the organic component of a complex additive to $0.1 \mathrm{wt} . \%$ alters the nature of the diluting action, thus, an increase in the quantity of the phosphate component leads to a monotone decrease in viscosity

- use of a complex additive yields a $30-40 \%$ decrease in the viscosity of the slip

\section{CONCLUSION}

The addition of surface-active substances, such as grinding intensifiers, produces a $3-7 \%$ increase in the yield of fine fractions of comminuted material under comparative comminuting conditions or a decrease in the length of the process of comminution of the material until the same indicators of the granular composition are achieved. This makes it possible to achieve a $5-7 \%$ savings in the energy spent on the process of fine grinding of materials and to decrease the expenditures on the operation of the grinding equipment.

In the case of comminution of roasted serpentinite, additives on a nonaqueous base are more effective and make it possible to realize a $10-20 \%$ increase in the yield of fine fractions.

The use of Litoplast $\mathrm{M}$ series diluents both individually and as a component of a complex additive with phosphonic electrolytes yields a $30-40 \%$ decrease in the viscosity of clay-free slip, which is equivalent to a $30-40 \%$ decrease in its moisture content with preservation of the rheological properties and, correspondingly, a decrease in the cost of energy carriers in subsequent drying of the slip. 